\title{
Clinical effects of a 'Human-Computer' merge
}

\begin{abstract}
It appears inevitable that technology, and specifically the internet, is set to continue playing a significant role in our lives. The interaction between humans and machines brings unprecedented changes to the way our health is affected. In this editorial, I am exploring four areas where human interaction with technology may impact on health, sometimes in ways we may not be aware of. This may help us devise interventions which carry therapeutic benefits for all participating humans. The discussion explores certain practical ways where technology may impact on our everyday life, as well as socio-cultural implications, evolutionary consequences, and discrete biological changes which may originate from our integration with digital communication technologies. Although there are still unforeseen problems with the manner such technology is progressing, we must embrace these new developments in order to adapt successfully to our new ecosystem. For a large proportion of humanity, this new ecosystem is no longer formed by several interacting species, but by just two main elements: humans and machines. The information exchange between these two elements creates new biological and cognitive challenges which have wide repercussion on our organism. A successful adaptation to these new challenges will lead to an improved and prolonged health span, and perhaps even the elimination of age-related dysfunction.
\end{abstract}

Keywords: Human-machine interaction; Health apps; Techno-culture; Cognition; Intentional evolution; Indispensable soma hypothesis

Core Tip: It is imperative to embrace technological change in order to be able to adapt to our new environment. By doing so, we open up new and hitherto unforeseen opportunities in the social, evolutionary, and biological sense, which may significantly change our health.

\section{INTRODUCTION}

Technology is continually impacting on our activities of everyday life. While there are huge benefits associated with this, there are also certain drawbacks ${ }^{[1]}$. With regards to health, technology may be used in order to provide answers to health challenges, and help us devise interventions in order to reduce the risk of disease, and improve general wellbeing. It is therefore important to examine certain aspects of these technological innovations, and identify areas where we may expect health gains. Here, I am going to discuss four broad areas where technology (and, particularly, digital communication technology and the internet) is translated into clinical, everyday health consequences. I will also explore certain very controversial or speculative socio-cultural and evolutionary concepts, some of which may contradict current general health advice, but are necessary in providing the lifestyle basis suited to a more technologically-dependent human. One such speculation is that exposure to information via digital communication technologies carries such an energetic burden upon our cognitive processes, that it may result in a shift of the evolutionary 
status quo (i.e. evolution by natural selection) to a different, more person-based and 'intentional' evolutionary model.

\section{DISCUSSION}

The four major aspects of human-computer integration are:

\section{Practical and applied elements}

The use of digital communication technology improves knowledge creation, and disseminates information mined from the internet, which may be used in order to improve health ${ }^{[2]}$. The use of data mining may be useful in a variety of ways (Table 1 ).

Table 1. Data used in order to improve health

\begin{tabular}{|l|l|l|}
\hline Domains & Details & Clinical result \\
\hline $\begin{array}{l}\text { Governmental } \\
\text { organisations }\end{array}$ & $\begin{array}{l}\text { Gathering and using information in order to formulate } \\
\text { health policies }^{[3]}\end{array}$ & $\begin{array}{l}\text { Population } \\
\text { health } \\
\text { improves }\end{array}$ \\
\hline $\begin{array}{l}\text { Researchers and } \\
\text { clinicians }\end{array}$ & $\begin{array}{l}\text { Using information from the internet in order to devise new } \\
\text { therapies and interventions }^{[4]}\end{array}$ & $\begin{array}{l}\text { Drug discovery, } \\
\text { Applied } \\
\text { therapies }\end{array}$ \\
\hline $\begin{array}{l}\text { Big data (the } \\
\text { generation of } \\
\text { information on } \\
\text { everything, plus } \\
\text { our ability to } \\
\text { analyse and } \\
\text { apply such } \\
\text { information) }\end{array}$ & $\begin{array}{l}\text { Can be used in prevention, prediction of epidemics, and } \\
\text { forecasting of health models } \\
\text { and }{ }^{[5]} \text {. The data can be compared } \\
\text { patients, and it can enable sophisticated predictive } \\
\text { modelling, identifying specific health threats. }\end{array}$ & $\begin{array}{l}\text { Improved } \\
\text { disease } \\
\text { management } \\
\text { and treatment }\end{array}$ \\
\hline
\end{tabular}

Apart from actual information gathering, technology may help us remain healthy through physical means. Consider for instance, wearable devices which monitor health status, and technology which enhances our function ${ }^{[6]}$. Concepts such as The Internet of Things ${ }^{[7,8]}$, and the Internet of Everything ${ }^{[9]}$ also play an important role here by integrating the use of such devices within an allencompassing, mutually-influencing and evolving system. For example, there is intense research into developing wearable devices and other sensors which may be able to identify early signs of medical emergencies (such as heart rhythm abnormalities) and then initiate appropriate response ${ }^{[10]}$. Other examples include health apps, such as calorie counting and nutritional aids, carbon monoxide and pollution risk sensors, sleep pattern monitoring, and many others such as Fitbit $^{\mathrm{TM}}$, Jawbone ${ }^{\mathrm{TM}}$ and Samsung Gear Fit ${ }^{\mathrm{TM}}$ devices. In addition, devices may not only be able to sense abnormalities, but may also administer pharmacological treatment, for example a device that senses low glucose and then administers insulin or metformin ${ }^{[11]}$.

There will soon come a time when such devices will become much more customised and fine-tuned to the personal and unique needs of the individual user, forming an even closer human-machine integration, where the line between the biological and the digital is increasingly blurred. Early examples of such developments include the Brain Gate neural interface system ${ }^{[12]}$ where brain 
sensory implants transform signals originating from specific brain regions, decode these signals and then transmit them to specified external devices or robots, in order to achieve movement ${ }^{[13,14]}$.

Although there is still a lot to be learned ${ }^{[15]}$ it remains highly likely that this integration will enable us to utilise technology to an even greater degree. If we remain well-embedded within a technological environment, our chances of being diagnosed, treated and cured are thus increased.

\section{Socio-Cultural consequences}

New technology continually generates helpful appliances, labour-saving tools, and interventions which reduce redundant and repetitive work. When people have less physical work to do, they are free to engage in more cognitive and creative activities. These tools also improve the general standard of living of many people, and enhance health indirectly through, for example:

* Appropriate architectural initiatives, which subsequently impact on health and well-being ${ }^{[16]}$

* Improved communication ${ }^{[17]}$ and spread of ideas. This is helpful both in the social sense and with regards to mental well-being

* Direct impact on social prosperity ${ }^{[18]}$

*New methods of education, conflict resolution and promotion of peace ${ }^{[19]}$

However, new problems and issues appear as technology develops. For instance there are problems with 'knowledge coupling' between the human and the technological device. This may be due to inconsistencies between human decision-making and technological (software) errors in design which affect machine decision-making ${ }^{[20]}$.The role of the clinician and health practitioner will have to be redefined in view of the increasing use of technology. This technology may create a false sense of security whereby the operator feels confident to rely on technological system's advice, even when the advice may later prove not to be correct ${ }^{[21]}$.

An exciting prospect with immense socio-cultural potential is brain to brain communication. This is an emerging discipline which aims to facilitate direct exchange of information between brains without the need to use language or keyboards ${ }^{[22]}$. The communication from one brain to another may be implemented through wireless means ${ }^{[23]}$, which means that a brain becomes a participant of increasing relevance in a technological environment. This has enormous potential applications to health, and although the technical problems still remain formidable, the outlook is positive ${ }^{[24]}$.

These developments are slowly shifting the emphasis from the physical to the cognitive, which results in a change in our evolutionary realities, as described below. In a society which is increasingly reliant on cognition, there will be more focus on self-generated thinking, a tendency to engage in creative, imaginative, goal-directed, divergent and abstract behaviour, and enhanced brain activities. In this respect we need to re-evaluate the relevance of the health information and advice we give. A society which leans more towards cognition, will have specific requirements with regards to lifestyle factors which are not met by the currently-accepted advice. For instance, we need to account for appropriate nutrition which is more suited to those who spend long hours with computers ${ }^{[25-27]}$, and aim for less physical exercise but more activities which align with a highly cognitive lifestyle ${ }^{[28,29]}$.

3. Evolutionary. The use of the internet by significant numbers of people creates intellectual capital (large groups of well-connected people) which can act as a catalyst for further knowledge 
creation ${ }^{[30]}$. Society can then adapt to the increasing knowledge, which provides further scope for development, improvement of the human condition and more creativity ${ }^{[31]}$.

Technology influences the way we adapt and evolve. It may change our evolutionary process, with a reduced emphasis on natural selection, and more emphasis on change which depends on artificial, intentional means. For instance, Mahmoudi et al. ${ }^{[32]}$ have shown that exposure to electromagnetic radiation from Wi-Fi routers may contribute to male infertility. Furthermore, use of laptops is also associated with reduced male fertility ${ }^{[33]}$. Studies such as these are inevitably reported in the popular media with an adverse slant, although at a deeper level reflect how technology is affecting our adaptation and stress response processes. Factors such as pollution, industrial chemicals and other environmental insults may have an overall evolutionary value, or at least play a role in shaping our future. There is evidence (Table 2 ) that those living in a technological environment are more likely to experience a reduction of reproduction, mirrored by an increase in health and lifespan (the $r-K$ selection model) ${ }^{[34]}$. This is discussed below.

\section{TABLE 2}

Those living in highly technological environments may experience a variety of events which are directly or indirectly related to technology. These events may then reduce reproductive processes (and thus improved longevity) ${ }^{[35]}$.

\begin{tabular}{|l|l|}
\hline Health change & Description \\
\hline Reduced sperm count & $\begin{array}{l}\text { There appears to be a general decline in the numbers } \\
\text { and quality of human sperm over the past } 50 \text { years }{ }^{[36]}, \\
\text { with the sperm concentration falling by about } 2 \% \text { a } \\
\text { year in certain groups of young men }{ }^{[37]} .\end{array}$ \\
\hline Increased testicular cancer & A general increase has been reported ${ }^{[38]}$ \\
\hline hypospadias & $\begin{array}{l}\text { Several studies suggest a general increases in } \\
\text { cryptorchidism and hypospadias. Some countries have } \\
\text { seen increases in such cases from around } 2 \% \text { to now } \\
\text { over } 8 \% \text { of the population }\end{array}$ \\
\hline Increase in prostate cancer
\end{tabular}

Certain authors have claimed that as intelligence, cognition, technology, and society improve, childlessness increases ${ }^{[41]}$ :

* The proportion of childless couples in some developed countries such as Germany and Japan is increasing progressively, and is now around $30 \%{ }^{[42]}$

* Fertility has declined by $9 \%$ in just 4 years in the USA and it is falling more globally as nations become more developed ${ }^{[43]}$ 
* Fertility is falling in Russia ${ }^{[44]}$ and in certain African countries as society becomes more technological[ ${ }^{[45]}$.

The above facts point to an apparent association between decline in reproduction, increase in technology and increase in health/longevity. This is supported by a mathematical model of population growth, based on a well-studied ' $\mathrm{r}-\mathrm{K}$ ' selection model ${ }^{[46]}$, which distinguishes between two different environments. In a situation where there is prolonged and sustained environmental uncertainty, high levels of risk and increased danger, the population of any given species grows according to the ' $r$ ' model with increased reproduction and shorter lifespans. This makes sense, in order to quickly replace members of the population when there is a high risk of dying. When the environment is stable, safe and well-controlled, then population grows according to the ' $\mathrm{K}$ ' model with reduced fertility and prolonged, healthier lifespans. Therefore, considering that our current environment (in developed countries) tends to be socially and politically safe, well-controlled with medical and health technologies, and more stable, it is reasonable to assume that the human population in such countries will grow according to the $\mathrm{K}$ model with increasing lifespans, improved long-term health and reduced fertility. What we are seeing here is that technology is not only altering our lifestyle but it is also gradually downgrading the importance of reproduction ${ }^{[47]}$.

4. Biological. This is the most speculative and yet game-changing aspect of a human-computer interaction. The sheer magnitude of information load and the increased knowledge we are exposed to, creates new biological situations ${ }^{[48]}$, which may have a deep impact on our health. I have speculated that such an exposure to new information can influence our somatic repair processes and resource allocation mechanisms ${ }^{[49]}$. This may ultimately up-regulate our biological function directly, in a way that is radically different than Darwinian evolution by natural selection.

Elsewher ${ }^{[50]}$, I discussed the Indispensable Soma Hypothesis. This suggests: "humans who are suitably integrated within a technological, information-rich, cognitive environment, and who are indispensable for the adaptability of such environment, may experience a reversal of their resource allocation priorities from the germline to the soma, resulting in improved somatic repair and a progressive reduction of age-related degeneration". The exposure to increased information originating from a highly technological environment may invoke natural biological principles and conserved signalling mechanisms, which then improve somatic repair and result in better function. For instance, I have discussed how cognitive information originating from the internet may upregulate neuronal endoplasmic reticulum stress response factors, and this regulates apoptosis in the germ line $\mathrm{e}^{[50]}$. In addition, such cognitive information may also play a part in regulating the commitment of spermatogonial stem cells to function as (mature) adult neurons ${ }^{[51]}$.

But it is not just the fact that positive information has a role to play here. Other factors may be involved. Living in a technological society is associated with certain situations which are commonly believed to be negative, but instead play a wider, more positive role. For instance, the 'radiation smog' created by devices such as mobile telephones, Wi-Fi etc., may initiate positive stress signalling (hormetic effects), which then modify several health parameters. It was shown that exposure to low dose radiation may help rescue living neurons from degeneration, irrespective of the mechanism of degeneration involved ${ }^{[52]}$. Much more research is needed in order to describe these notions in detail.

All of the above mechanisms share common frontiers and are mutually cooperative and reciprocally influencing (figure 1). 




Figure 1. Interrelationship between the four domains of how technology affects life-span extension. Each domain influences and is being influenced by all others.

\section{CONCLUSION}

Although technology is conspicuous in our life, its effects are not always immediately obvious, specifically with regards to health. It is not just a matter of technology improving our health through the use of devices, aids, apps and data management. This is easily foreseeable. What is not immediately obvious is that technology and its consequences (greenhouse gasses, environmental chemicals, and countless other subtle changes) are modifying our evolution process. For instance, a direct consequence of technology is pollution, which may be affecting fertility and thus improving longevity via (hitherto) elusive evolutionary mechanisms. As technology is increasingly driving us to abandon our reliance on physical activities and, instead, concentrate more on cognition, health advice which was suitable until now may not be appropriate any longer. This may be true for at least some sections of humanity who place more emphasis on cognition and those who are deeply embedded within an information-rich ecosystem. New interventions need to be devised based more on improving cognitive health and less on improving physical health. We need to reach an ideal balance with regards to human-computer merge, in order to enjoy maximum benefits with the minimum drawbacks, although it is likely that technology will totally transform our concepts regarding health. 


\section{REFRENECES}

1 Crane M. 12 Worst Medical Technology Dangers. [accessed 2016 March 7]. Available from: URL: http://www.medscape.com/features/slideshow/tech-dangers

2 Jiang S, Zhu X, Wang L. EPPS: Efficient and Privacy-Preserving Personal Health Information Sharing in Mobile Healthcare Social Networks. Sensors (Basel) 2015; 15(9): 22419-38. doi:

$10.3390 / \mathrm{s} 150922419$.

3 Health Profiles. [accessed 2015 Dec 4]. Available from: URL:

http://www.apho.org.uk/default.aspx?QN=P HEALTH PROFILES

4 Brossette SE, Sprague AP, Hardin JM, Waites KB, Jones WT, Moser SA. Association Rules and Data Mining in Hospital Infection Control and Public Health Surveillance. J Am Med Informatics Ass: JAMIA 1998; 5(4): 373-381

5 Murdoch TB, Detsky AS. The Inevitable Application of Big Data to Health Care JAMA. 2013; 309(13):1351-1352. doi:10.1001/jama.2013.393

6 Rowland NC, Breshears J, Chang EF. Neurosurgery and the dawning age of Brain-Machine Interfaces. Surg Neurol Int 2013; 4(Suppl 1): S11-4. doi: 10.4103/2152-7806.109182

7 Konstantinidis El, Bamparopoulos G, Billis A, Bamidis PD. Internet of things for an age-friendly healthcare. Stud Health Technol Inform 2015; 210: 587-91. PMID: 25991216

8 van Hoof J, Kort HS, Rutten PG, Duijnstee MS. Ageing-in-place with the use of ambient intelligence technology: perspectives of older users. Int J Med Inform 2011; 80(5): 310-31. doi:

10.1016/j.ijmedinf.2011.02.010

9 Louchez A. The Internet of Things Is a Secular Transformation. IOT Journal. [accessed 2016 Jan 4]. Available from: URL: http://www.iotjournal.com/articles/view?13003

10 Dallas E. Having a Heart Attack or Stroke? Your iPhone Knows. [accessed 2016 Feb 4]. Available from: URL: http://www.everydayhealth.com/heart-health/having-a-heart-attack-or-stroke-youriphone-knows-6152.aspx

11 Lee H, Choi TK, Lee YB, Cho HR, Ghaffari R, Wang LW, Choi HJ, Chung DT, Lu N, Kim DH. A graphene-based electrochemical device with thermoresponsive microneedles for diabetes monitoring and therapy. Nat Nanotechnol. 2016 Mar 21. doi: 10.1038/nnano.2016.38. [Epub ahead of print]

12 Bacher D, Jarosiewicz B, Masse NY, Stavisky SD, Simeral JD, Newell K, Oakley EM, Cash SS, Friehs G, Hochberg LR. Neural Point-and-Click communication by a person with incomplete locked-In syndrome. Neurorehabil Neural Repair 2015;29(5):462-71. doi: 10.1177/1545968314554624

13 Malik WQ, Hochberg LR, Donoghue JP, Brown EN. Modulation depth estimation and variable selection in state-space models for neural interfaces. IEEE Trans Biomed Eng. 2015; 62(2):570-81. doi: 10.1109/TBME.2014.2360393

14 Downey JE, Weiss JM, Muelling K, Venkatraman A, Valois JS, Hebert M, Bagnell JA Schwartz AB, Collinger JL. Blending of brain-machine interface and vision-guided autonomous robotics improves 
neuroprosthetic arm performance during grasping. J Neuroeng Rehabil. 2016; 13(1) 28. doi: 10.1186/s12984-016-0134-9

15 Lu CW, Patil PG, Chestek CA. Current challenges to the clinical translation of brain machine interface technology. Int Rev Neurobiol 2012; 107: 137-60. doi: 10.1016/B978-0-12-404706-8.000085

16 Architecture for health. [accessed 2016 March 23]. Available from: URL: https://www.architecture.com/Explore/Stories/Architectureforhealth.aspx

17 Diéguez L. The importance of digital communication in the healthcare industry. [accessed 2016 March 25]. Available from: URL: http://en.blog.zyncro.com/2012/08/03/the-importance-of-digitalcommunication-in-the-healthcare-industry/

18 Sum S, Mathews, MR, Pourghasem M, Hughes I. Internet Technology and Social Capital: How the Internet Affects Seniors' Social Capital and Wellbeing. J Computer-Mediated Comm 2008: 14: 202220. doi: 10.1111/j.1083-6101.2008.01437.x

19 Laouris Y. Anastasiou H. The introduction of IT in the lives of children as a service to global peace. [accessed 2016 March 23]. Available from: URL:

http://www.mlearn.org.za/CD/papers/Laouris\%20\&\%20Anastasiou.pdf

20 Coiera E. Technology, cognition and error. BMJ quality \& safety 2015; 24(7), 417-422. doi: 10.1136/bmjqs-2014-003484.

21 Dror IE, Harnad, S. (eds.) (2008). Cognition Distributed: How Cognitive Technology Extends Our Minds. (258 pp.) John Benjamins, Amsterdam

22 O'Doherty JE, Lebedev MA, Ifft PJ, Zhuang KZ, Shokur S, Bleuler H, Nicolelis MA. Active tactile exploration using a brain-machine-brain interface. Nature 2011; 479(7372): 228-31. doi: 10.1038/nature10489

23 Li G, Zhang D. Brain-Computer Interface Controlled Cyborg: Establishing a Functional Information Transfer Pathway from Human Brain to Cockroach Brain. PLoS One 2016; 11(3): e0150667. doi: 10.1371/journal.pone.0150667. eCollection 2016

24 Tabot GA, Kim SS, Winberry JE, Bensmaia SJ. Restoring tactile and proprioceptive sensation through a brain interface. Neurobiol Dis 2015; 83:191-8. doi: 10.1016/j.nbd.2014.08.029

25 Kann O, Papageorgiou IE, Draguhn A. Highly energized inhibitory interneurons are a central element for information processing in cortical networks. J Cereb Blood Flow Metab 2014; 34(8): 1270-82. doi: 10.1038/jcbfm.2014.104

26 Galow LV, Schneider J, Lewen A, Ta TT, Papageorgiou IE, Kann O. Energy substrates that fuel fast neuronal network oscillations. Front Neurosci 2014; 8: 398. doi: 10.3389/fnins.2014.00398

27 Brickman AM, Khan UA, Provenzano FA, Yeung LK, Suzuki W, Schroeter H, Wall M, Sloan RP, Small SA. Enhancing dentate gyrus function with dietary flavanols improves cognition in older adults. Nature Neuroscience 2014; 17: 1798-1803. doi: 10.1038/nn.3850.

28 Kyriazis M. Systems neuroscience in focus: from the human brain to the global brain? Front Syst Neurosci 2015; 9: 7. eCollection 2015. doi: 10.3389/fnsys.2015.00007 
29 Kyriazis M. A cognitive-cultural segregation and the three stages of aging. Curr Aging Sci 2016; 9(2): 81-6. PMID: 26651458

30 Hussi T. Reconfiguring knowledge management: Combining intellectual capital, intangible assets and knowledge creation, ETLA Discussion Papers, The Research Institute of the Finnish Economy (ETLA) 2003; 849

31 Mehralian G, Nazari JA, Akhavan P, Rasekh HR. Exploring the relationship between the knowledge creation process and intellectual capital in the pharmaceutical industry. The Learning Organization 2014; 21(4): 258-273

32 Mahmoudi R, Mortazavi SMJ, Safari S, Nikseresht M, Mozdarani H, Jafari M, A. Microwave Electromagnetic Radiations Emitted from Common Wi-Fi Routers Reduce Sperm Count and Motility. International Journal of Radiation Research. 2015 [accessed 2016 March 24]. Available from: URL: https://www.researchgate.net/publication/277248261 Microwave Electromagnetic Radiations Em itted from Common Wi-Fi Routers Reduce Sperm Count and Motility

33 Mortazavi SMJ, Tavassoli A, Ranjbar F, Moammaiee P. Effects of Laptop Computers' Electromagnetic Field on Sperm Quality. J Reprod Infertil 2010; 11(4): 251-258

34 Pianka ER. On $r$ and K selection. American Naturalist 1970; 104 (940): 592-597

35 Tabatabaie V, Atzmon G, Rajpathak SN, Freeman R, Barzilai N, Crandall J. Exceptional longevity is associated with decreased reproduction. Aging (Albany NY) 2011; 3(12): 1202-5. PMID: 22199025

36 Sharpe RM. Sperm counts and fertility in men: a rocky road ahead. EMBO Rep 2012; 13(5): 398403. doi: 10.1038/embor.2012.50.

37 Handelsman DJ, Cooper TG. Falling sperm counts and global estrogenic pollution: what have we learned over 20 years? Asian J Androl 2013; 15(2):159-61. doi: 10.1038/aja.2013.8

38 Shanmugalingam T, Soultati A, Chowdhury S, Rudman S, Van Hemelrijck M. Global incidence and outcome of testicular cancer. Clinical Epidemiology 2013; 5, 417-427. doi 10.2147/CLEP.S34430

39 Giwercman A, Giwercman YL. Environmental factors and testicular function. Best Pract Res Clin Endocrinol Metab 2011; 25(2): 391-402. doi: 10.1016/j.beem.2010.09.011

40 Haas GP, Delongchamps N, Brawley OW, Wang CY, de la Roza G. The Worldwide Epidemiology of Prostate Cancer: Perspectives from Autopsy Studies. The Canadian J Urol 2008; 15(1), 3866-3871. PMID: 18304396

41 Kanazawa S. The Intelligence Paradox: Why the Intelligent Choice Isn't Always the Smart One. 2012. John Wiley \& Sons. Hoboken New Jersey

42 Hara T. Increasing Childlessness in Germany and Japan: Toward a Childless Society? Int J Japanese Sociol 2008; 17: 42-62. doi: 10.1111/j.1475-6781.2008.00110.x

43 Population reference Bureau 2014. [accessed 2016 March 22]. Available from: URL: http://www.prb.org/Publications/Datasheets/2014/2014-world-population-data-sheet/us-fertilitydecline-factsheet.aspx

44 Zakharov SV, Ivanova El. Fertility Decline and Recent Changes in Russia: On the Threshold of the Second Demographic Transition. [accessed 2016 March 27]. Available from: URL:

http://www.rand.org/pubs/conf proceedings/CF124/CF124.chap2.html 
45 Caldwell JC, Orubuloye IO, Caldwell P. Fertility Decline in Africa: A New Type of Transition? Population and Development Review 1992;18(2):211-242

46 Heylighen F. From Quantity to Quality of Life: $r-K$ selection and human development. [accessed 2016 March 13]. Available from: URL:

http://citeseerx.ist.psu.edu/viewdoc/summary?doi=10.1.1.89.3618

47 Last C. Human evolution, life history theory, and the end of biological reproduction. Curr Aging Sci 2014; 7(1): 17-24. PMID: 24852016

48 Kyriazis M. Reversal of informational entropy and the acquisition of germ-like immortality by somatic cells. Curr Aging Sci 2014; 7(1): 9-16. PMID 24852017

49 Kyriazis M. Environmental challenges may impact on somatic repair 2015. [accessed 2016 March 22]. Available from: URL: https://peeri.com/preprints/1560/

50 Kyriazis M. The Indispensable soma hypothesis 2016. [accessed 2016 March 23]. Available from: URL: https://figshare.com/articles/New draft item The Indispensable Soma Hypothesis/3079732

51. Kyriazis M. Engagement with a technological environment for ongoing homoeostasis maintenance. In Challenging Ageing: The anti-senescence effects of Hormesis, Environmental Enrichment, and Information Exposure 2016. Bentham Science Publishers, UAE. In press

52 Otani A, Kojima H, Guo C, Oishi A, Yoshimura N. Low-dose-rate, low-dose irradiation delays neurodegeneration in a model of retinitis pigmentosa. Am J Pathol 2012; 180(1): 328-36. doi: 10.1016/j.ajpath.2011.09.025 